\title{
The laws of modality
}

\author{
Matthew Tugby ${ }^{1}$ D
}

Accepted: 11 January 2022/Published online: 11 February 2022

(C) The Author(s) 2022

\begin{abstract}
Nomic realists have traditionally put laws to work within a theory of natural modality, in order to provide a metaphysical source for causal necessitation, counterfactuals, and dispositions. However, laws are well-suited to perform other work as well. Necessitation is a widespread phenomenon and includes (for example) cases of categorial, conceptual, grounding, mathematical and normative necessitation. A permissive theory of universals allows us to extend nomic realism into these other domains. With a particular focus on grounding necessitation, it is argued that the sorts of reasons for positing laws in the natural causal domain also apply in other domains. Laws might well be the source of all first-order modality.
\end{abstract}

Keywords Laws · Universals · Necessitation · Modality · Grounding · Essence

\section{Introduction}

Realist anti-Humean theories of natural laws have recently been a focus of attention in the metaphysics of science, especially the view that natural laws are relations of necessitation (of some sort) between universals (Dretske, 1977; Tooley, 1987; Armstrong, 1983). Interestingly, this version of nomic realism-which we may call a Necessary Connection (NC) view of laws-provides a recipe for explaining a wide range of necessitation cases in other domains, such as those involving grounding necessitation, categorial necessitation, conceptual necessitation, mathematical necessitation, and so on. As we shall see, the reasons for postulating nomic connections between universals in the case of natural necessitation carry over to these other forms of necessitation; postulating necessary connections between

Matthew Tugby

matthew.tugby@durham.ac.uk

1 Department of Philosophy, Durham University, 51 Old Elvet, Durham DH1 3HN, UK 
universals in these other cases might thus lead to a unified theory about necessitation. Curiously, though, NC theorists have focused almost exclusively on cases of natural necessity and have neglected the theory's wider explanatory potential. I suspect this is because NC theorists are holding on to an overly restrictive 'sparse' conception of universals; if we drop this restriction, the application of NC laws can be significantly extended.

In Sect. 2 I set out the NC theory of natural laws in detail. In Sect. 3 I provide examples of necessitation in other metaphysical domains. In Sect. 4 I focus on grounding necessitation, and show that the reasons for postulating NC laws in the case of natural necessitation carry over to these other cases; I also discuss reasons why few (if any) NC theorists have so far extended their view in this way. In Sect. 5 I discuss different ways in which the necessary connections between universals might arise in the various domains. Section 6 concludes, briefly discussing possible future lines of work on the topic of modality for laws theorists.

\section{Natural laws as relations between universals}

Within the domain of metaphysics, work on laws has focused mainly on laws of nature. Roughly speaking, statements of natural law describe the non-accidental, global behavioural patterns that we find in natural science. Such statements are generalizations of a certain sort. In the macroscopic cases that philosophers often discuss, law statements take the form of a universally quantified conditional, such as 'all salt dissolves in water'. However, in the more fundamental cases of physics, the laws typically take the form of functional mathematical equations, such as Coulomb's law, which express the dynamic relationships in which various physical quantities stand. Work has been undertaken by NC theorists elsewhere to show how functional laws can be accommodated within the NC framework (e.g. Armstrong, 1997), and in what follows I shall not say much more about the distinction between functional and non-functional laws. I merely introduce these different examples to illustrate that the various law statements all tell us about natural regularities of one sort or another.

In the metaphysics of science, there are different well-known theories about the source of the laws of nature. The central question is as follows: What is it that makes law statements true? Humeans and anti-Humeans disagree on the answer. Famously, Humeans offer a deflationary account, on which the truthmakers for law statements just are regularities of a certain sort-perhaps those regularities that allow us to systematize the worldly goings-on in a simple and elegant way (see Lewis, 1973: 72-77). Anti-Humeans, in contrast, think something more is needed. Among the many problems with the Humean framework (see Armstrong, 1983, Chs. 2-5 for a survey), a key objection is that it does not provide for enough modal 'oomph'. The nomic regularities are purely contingent, and although they hold globally, there is no underlying metaphysical reason why they do so. Although salt always dissolves in water (in suitably specified circumstances), there is no reason why salt must 
behave in this way. On this view, it looks like an incredible fluke that the world exhibits behavioural order (Strawson, 1987).

Anti-Humeans, in contrast, think that when a law of nature holds, the resultant behaviour must (in some sense) happen. To use Armstrong's example, 'if a quantity of uranium 235 reaches critical mass, then it has to disintegrate violently' (1997: 223). If you agree with Armstrong, then you will think that there is some sort of necessary connection between the critical mass of uranium 235 and disintegration. How, though, are such necessary connections to be understood?

A common anti-Humean strategy for explaining nomic necessitation is to utilize the resources of the theory of universals. We can speak of one state of affairs necessitating another in a particular case, but, as we saw above, law statements are generalizations, which is to say they tell us about how certain types of things or quantities behave. If laws consist in necessary connections of some sort, therefore, it is natural to appeal to a metaphysics of types, or universals, and say that laws are necessitation relations (of some sort) between universals. This is the view that I am calling the Necessary Connection (NC) theory. In metaphysics, universals are properties which are instantiated by particulars, and when distinct particulars instantiate the same universals they literally have something identical in common.

How, then, can a universals theorist account for natural laws? In some cases, laws will simply be of the form $\mathrm{N}(\mathrm{F}, \mathrm{G})$, where $\mathrm{F}$ and $\mathrm{G}$ refer to universals and $\mathrm{N}$ is the relation of nomic necessitation. Since the relation is itself a universal, laws turn out to be complex universals, or as Armstrong sometimes terms them, second-order states of affairs. With these universals in play, we can say that the generalizations described in law statements hold in virtue of those laws. In truthmaking parlance the idea is that the truthmaker for $<$ all Fs are Gs $>$ is $\mathrm{N}(\mathrm{F}, \mathrm{G})$. As well as playing a truthmaking role, these laws also explain their concrete instances. For example, when one first-order state of affairs causally necessitates another, this is explained by the fact that the universals involved stand in a nomic relation. Moreover, the law ensures that all instances of those relevant universals behave in the same way. This is guaranteed by the fact that universals are identical across their instances. We can think of second-order relations of necessitation as a kind of metaphysical glue: if property $F$ is metaphysically glued to property $\mathrm{G}$ (i.e. $\mathrm{N}(\mathrm{F}, \mathrm{G})$ ), then all instances of $\mathrm{F}$ must be glued to instances of $\mathrm{G}$, because those instances all involve the very same universals.

This is a very brief sketch of the NC theory. The theory was developed in slightly different ways in the 1970s and 80s by Dretske (1977), Tooley (1987) and Armstrong (1983; see Mumford, 2004, Ch. 6 for discussion of the differences), and defended more recently by Hildebrand $(2013,2018)$. The theory has also attracted some well-known criticisms, some of which I shall discuss later on. ${ }^{1}$ The theory has

\footnotetext{
1 There are also some well-known objections that I shall not discuss. For example, Lewis (1983: 40) complains that it is a mystery how Armstrong's nomic relation necessitates first-order regularities, and points out that calling the nomic relation a 'necessitation' relation does not really help. Along similar lines, van Fraassen (1989) poses the so-called 'inference problem' (van Fraassen 1989). For recent responses to this objection, see Schaffer (2016b), Coates (2021) and Wilsch (2021). I shall not discuss this work here because it is not my aim to provide a thorough defence of Armstrong's position. Rather, I argue that if the theory is plausible in the case of natural laws, then it is likely to be plausible elsewhere in metaphysics.
} 
been applied to different kinds of natural laws-such as probabilistic laws, functional laws, and laws with exceptions-and also used to shed light on counterfactuals. Different NC theorists also entertain different conceptions of universals. For example, in later work Armstrong (1997, Ch. 15) identifies universals with 'state of affairs types', which exist entirely through their token instances, while Tooley (1987: 669) leans towards a Platonic understanding of universals on which they exist independently of their instantiations-his theory having the benefit of accommodating uninstantiated laws. Fortunately, for current purposes we can set aside most of these finer details. One important point to note, though, is that according to Dretske, Tooley, and Armstrong, necessary connections between universals are external and metaphysically contingent. Once the connections hold within a universe, they cannot fail to hold in that universe, but it is nonetheless metaphysically possible that the laws could have been different. The connections, we might say, are physically necessary but not metaphysically so. However, one could accept that laws are relations between universals without accepting that the relations are external and contingent: indeed, such a view is held by those who favour a dispositional essentialist theory of laws (e.g. Swoyer, 1982; Ellis, 2001; Bird, 2007). According to this essentialist theory, the necessitation relations between universals are internal and metaphysically necessary, in the sense that those relations are part of the essences (or 'what it is to be') those universals. For the purposes of this paper, then, I classify universals-based versions of dispositional essentialism as NC theories (more on this in Sect. 5).

Finally, I note that there is an alternative realist theory of laws, the primitivist conception (Carroll, 1994; Maudlin, 2007), on which laws of nature are simply sui generis fundamental ontological entities. On this view, nothing much can be said about the nature of laws, metaphysically speaking, because they are at the fundamental level of reality. Primitivists like Carroll and Maudlin thus reject the attempt by $\mathrm{NC}$ theorists to give a more perspicuous metaphysical analysis of laws in terms of universals and the relations between them. Primitivists simply do not attempt to give a deeper metaphysical analysis. Nonetheless, primitivists and NC theorists are in agreement that laws cannot be reduced to patterns of behavioural regularity in the world, and thus they both oppose the Humean approaches to laws. ${ }^{2}$ Although the NC theory is the focus of this paper, I shall say a little more about this primitivist view in Sect. 5. For the time being, suffice to say that the NC theory promises to provide a more illuminating account of laws than primitivism, and offers the resources for articulating the relational structure that laws clearly seem to have.

Having outlined the NC theory of natural laws, we will begin to explore how a universals theorist could apply the NC theory to other areas of metaphysics.

\footnotetext{
${ }^{2}$ Maudlin motivates his approach, in part, by appealing to science: '...nothing in scientific practice suggests that one ought to try to reduce fundamental laws to anything else. Physicists simply postulate fundamental laws, then try to figure out how to test their theories; they nowhere even attempt to analyse those laws in terms of patterns of instantiation of physical quantities' (2007: 105).
} 


\section{Necessitation in other domains}

The NC laws posited by Dretske, Tooley, and Armstrong provide a metaphysical foundation for the laws we find in natural science. Indeed, in later work Armstrong (1997, Ch. 15.3) proposes that all natural laws supervene on the causal laws. That is to say, the fundamental nomic connection is a second-order causal connection whose instances are concrete causal sequences. However, it is far from obvious that NC laws should be limited in this way.

Cases in which one entity necessitates another are pervasive in metaphysics. In the grounding literature, for example, Grounding Necessitarianism is the default position (Bliss \& Trogdon, 2014, Sect. 5), according to which it is metaphysically necessary that a grounded entity exists if its (full) ground exists. ${ }^{3}$ Grounding is a metaphysical determination relation that explains why something is so. Grounding is everywhere: arguably, parts ground the wholes they compose; determinate properties ground determinable properties; sets are grounded in their members; mental states are grounded in physical states; normative properties are grounded in natural properties; and so on. ${ }^{4}$ Grounding is typically said to be a relation between facts or states of affairs (e.g. Rosen, 2010; Audi, 2012). Although grounding is often said to be closely analogous to causation (Schaffer, 2016a), there are obvious differences between grounding and the sort of causation in natural science that Armstrong is concerned with. For example, grounding is typically a synchronic relation, while many (if not all) cases of causation are diachronic; moreover, there is arguably a particularly intimate relationship between grounded entities and their grounds, in the sense that the former ontologically depend in some way on the latter. ${ }^{5}$ Nonetheless, grounding theorists certainly think that grounded entities exist and that they are numerically distinct from their grounds, and therefore we may regard grounding as a case of one thing necessitating another. Hence, if one thinks that NC laws are needed to explain causal necessities, it is surely not outlandish to think that NC grounding laws are needed to explain grounding necessities. If grounding relates facts or states of affairs, as is commonly thought, then presumably universals can be abstracted from those states of affairs and serve as the relata of the grounding laws. We explore this thought below.

Although in what follows we focus primarily on grounding necessitation, it is important to note that there are many other plausible cases of necessary connection.

\footnotetext{
3 This is not to say that Grounding Necessitarianism is universally held. For example, Leuenberger (2014) and Skiles (2015) have both argued that grounding is not necessary in every case. However, even if Grounding Necessitarianism is false as a general thesis, it is presumably not a complete accident as to what grounds what. As long as there are patterns of grounding regularity in the world, an NC account of grounding laws could still be utilized, with the proviso that the NC grounding laws are different in other possible worlds.

${ }^{4}$ I accept that some of these cases of grounding are more controversial than others; however, these are representative examples of grounding that can be found in recent literature. For example, Dasgupta (2014) and Schaffer (2017a, 2017b) have recently proposed physicalist grounding theories about the mental.

5 See also Rosen 2017, Sect. 1 for a discussion of other possible differences between metaphysical grounding and nomic explanations in science.
} 
For example, it is necessary that dogs are animals (categorial necessity); it is necessary that bachelors are unmarried men (conceptual necessity); it is necessary that 9 is the successor of 8 (mathematical necessity); it is necessary that an action involving murder is wrong (normative necessity); etc. If we are happy to posit NC laws in cases of natural or causal necessity, why not do the same in these other cases?

I expect two immediate forms of resistance. The first is to say that many of these other kinds of necessitation truths somehow explain themselves and therefore do not need truthmakers. This idea is often proposed in relation to conceptual, logical, and mathematical truths (e.g. Heil, 2018: 21-22). There is much to be said about this issue, but for the purposes of this paper I shall merely observe, in line with Armstrong (2004), that this issue should be 'up for grabs'. Like Armstrong, I find Truthmaker Maximalism - the view that all truths have truthmakers- to be an attractive hypothesis because it promises a unified realist treatment of all truths. Rather than dismissing Truthmaker Maximalism from the start, we should treat it as a hypothesis to be tested and see to what extent it can be confirmed.

Another source of resistance to the extension of NC laws is that even if these other kinds of necessary connection are to be grounded in reality, the NC theory is the wrong place to look because these other cases do not involve universals. But, again, this is controversial and the issue should be up for grabs. It is true that Armstrong was concerned with the 'sparse' universals of science (particularly in fundamental physics) when developing his theory of natural laws, but as I have noted elsewhere (Tugby forthcoming 2022: Ch. 10, Sect. 7), many philosophers have held that there are other kinds of universals. On Jubien's view, categorial universals like 'being a horse' and 'being an animal' are universals which stand in what he calls internal relations of 'entailment' (2009: 92-94). And in the philosophy of mathematics numbers are sometimes said to be universals. On Lowe's view numbers are universals whose instantiations are of sets (1993), and according to the theory of Bigelow and Pargetter (1990, Ch. 8), numbers are generated through relations of proportion. Lowe also takes concepts to be universals, whose instantiations are 'ways of thinking' about things (2013: 97). ${ }^{6}$ On such a view, it would not be surprising if concepts stood in internal relations of entailment, and on some theories of concepts they are precisely individuated (in part) by such relations. To give another example, in the metaphysics of words Platonism is taken be a serious contender (Miller, 2020: Sect. 2.1). With all such universals in play, it is not absurd to think that the source of categorial, mathematical, conceptual, and linguistic necessary connections might lie in relations between these various universals. This is, of course, speculative, and it would take a lot of work to show that all of these theories of universals are plausible. However, by motivating the case for NC laws in the case of grounding necessitation, I hope to show that further work by universals theorists in these other areas could prove fruitful.

\footnotetext{
${ }^{6}$ Here 'entities' should be loosely construed, since concepts apply not only to ordinary objects. For example, certain logical concepts could be regarded as ways of thinking about logical connectives. This would open up the possibility of explaining logical necessities in terms of the relations between logical concepts.
} 


\section{Laws of grounding}

Let us now focus specifically on the case of grounding necessitation. What reasons are there for thinking that laws are needed to explain why, say, certain parts necessitate certain wholes, why certain determinates ground certain determinables, why certain physical states ground certain mental states, and so on? To be sure, not all grounding theorists think that grounding laws are needed to explain why grounds necessitate the grounded. According to one recent theory in the meta-grounding debate, it is the grounding entity all by itself that fully explains why grounding occurs (Bennett, 2017; deRosset, 2013). This view is not widely accepted, however, and the need for grounding laws has been discussed recently by Wilsch (2015), Schaffer (2017a, 2017b) and Rosen (2017). Schaffer's argument for grounding laws is what I call the argument from explanatory gaps. To use an example from Schaffer (2017a), if one does not understand why a certain arrangement of two hydrogen atoms and one oxygen atom grounds water, it will not be very illuminating to be told that this arrangement of two hydrogen atoms and one oxygen atom explains the very fact that water is grounded by that arrangement (see also Wallner, 2018: Sect. 10). This explanatory problem comes out most clearly in the case of grounding physicalism, on which physical states ground mental states, because the link between physical states and mental states is far from transparent. An obvious way for a grounding theorist to fill this gap, then, is to appeal to psycho-physical grounding laws.

Schaffer goes on to argue that explanatory gaps afflict all cases of grounding. This idea was not widely held when the contemporary notion of grounding first came on the scene. For example, Kit Fine suggests in numerous places (e.g. Fine, 2001) that immediate metaphysical grounding is a gap-free explanatory relation. If Fine is right, then there seems to be an important difference between causation and grounding, because there do seem to be explanatory gaps between causes and effects that can be filled by natural laws. However, Schaffer (2016a) argues that grounding and causation are more similar than many have appreciated (see also Wilson, 2018). In the case of grounding, the explanatory gaps tend to go unnoticed because the underlying metaphysical principles are so familiar to us. To use one of Schaffer's examples, the fact that the combination of two $5 \mathrm{~kg}$ masses necessitates a $10 \mathrm{~kg}$ mass does not seem at all puzzling, but this is not because it is, say, an analytic truth that a $10 \mathrm{~kg}$ mass is grounded in this way. The reason why this instance of grounding seems transparent is that we are familiar with an underlying metaphysical law, namely, that (Newtonian) mass is additive (Schaffer, 2017a: 11-12). According to this theory of grounding, then, grounding explanations are a tripartite affair: they involve an input (the ground), the output (the grounded), and a link between the two. The link between the two is a law or principle of metaphysics (Schaffer, 2017a, 2017b). We can summarize the argument from explanatory gaps as follows:

The Argument from Explanatory Gaps: By itself, a grounding entity does not deliver a complete explanation for the entity(s) that it grounds. There is an explanatory gap which has to be filled by laws of metaphysics. 
In the mass example, the law will take the form of a functional additive law. Thus, for NC theorists this law of metaphysics could be understood along the lines of Armstrong's account of natural functional laws (1983, Ch. 7; 1997, Ch. 16). ${ }^{7}$

There is also a related benefit that comes with acceptance of $\mathrm{NC}$ grounding laws. Grounding laws not only fill the explanatory gaps in specific instances of grounding; they also allow us to explain the global grounding patterns. As explained earlier, according to the NC view, laws govern all their instances because such laws are themselves made up of universals, and universals are strictly identical in all their instances. Hence, if a law holds in one case, it holds across the board. Let us call this the argument from grounding patterns. We can summarize the argument as follows:

Argument from Grounding Patterns: Grounding entities of the same kind always ground other entities of a certain kind. These general patterns are explained by laws of metaphysics.

Dasgupta (2014) proposes this kind of argument for a view he calls 'connectivism' about grounding. ${ }^{8} \mathrm{He}$ asks the following question in relation to an example involving a conference:

According to $(\mathrm{F})$, the fact that event e contains people engaged in $\mathrm{C}$-activities grounds the fact that $\mathrm{e}$ is a conference. But now consider another event $\mathrm{e}^{\prime}$ in which other people engage in $\mathrm{C}$-activities. If we investigate this other event we will find (I submit) that it is also a conference, and moreover is a conference in virtue of those people engaging in $\mathrm{C}$-activities ... Why? Why do we never find an event where people engage in $\mathrm{C}$-activities but where those activities do not ground a conference? The pattern is striking-what explains it? (2014: 570).

Dasgupta's answer is that there are general metaphysical connections between certain activities and conferences. According to Dasgupta's preferred version of this view, this connection is an essential one that lies in nature of conferences (see also Rosen, 2010 and Kment, 2014). However, Dasgupta accepts that the general connections in question could be regarded as a metaphysical law of some kind (2014: 568). ${ }^{9}$ Moreover it is noteworthy that although Dasgupta does not explicitly say so, if connectivism is to explain general grounding patterns in the way he wishes, the connections must surely pertain to type-entities rather than tokens. So, although universals are not discussed at all in Dasgupta's 2014, it is not unreasonable to think that universals are needed in his connectivist metaphysics;

\footnotetext{
7 On Armstrong's 1997 view, functional laws are relations between determinable universals (1997: 246-48).

${ }^{8}$ See also Wilsch (2015), who argues that grounding laws are able to explain what he calls the 'Grounding-principle' (among others). Wilsch's Grounding-principle says that if an object has some property in virtue of having some other property, then the former property is in general sufficient for the latter' (2015: 3295). However, Wilsch does not develop his theory of grounding laws along NC lines. Instead, he leans towards a primitivist approach on which laws of metaphysics are fundamental truths (2015: 3307). See Sect. 5 for further discussion of primitivist conceptions of laws.

9 A related benefit of this view, which Dasgupta discusses, is that these general connections can underpin predictions about grounding (2014: 569).
} 
or, at least, viewing general connections as connections between universals is one obvious way of developing the connectivist position.

Note also that even if the general connections are generated by the essences of the relevant universals, this does not prevent us from thinking of those relations as laws. For example, and as noted earlier, in the literature on natural modality there are versions of dispositional essentialism on which there are essential nomic connections between properties (e.g. Bird, 2007; Swoyer, 1982; Yates, 2018). Unlike Dretske-Tooley-Armstrong-style laws, which are metaphysically contingent, essentialist laws are necessary internal relations between universals. This does not mean that such relations are not real, however, nor does it mean that they do not have important explanatory work to do (see Tugby, 2016a, forthcoming 2022, and below). We shall discuss this issue further in the next section when we discuss the different ways in which necessitation relations arise.

In summary, we have focused on two related reasons for $\mathrm{NC}$ theorists to extend their theory of laws to grounding laws. The idea would be that instances of grounding are governed or explained by metaphysically necessary laws holding between universals. Such laws can fill explanatory gaps and explain general grounding patterns. That such laws are well suited to play these roles is made clear by the fact that precisely the same sorts of arguments are employed by NC theorists in the case of natural modality. Indeed, both Dasgupta (2014: 568) and Schaffer (2017b: Sect. 2.1) acknowledge that the reasons for accepting grounding laws are analogous to those for accepting causal laws. This comes out most clearly through examining the work of Armstrong. In his 1997 discussion of laws, Armstrong starts by asking rhetorically 'is there not a possibility that different instantiations of a universal should give rise to different effects, even in an environment otherwise identical in nature?' (1997: 222). Here Armstrong is pointing to an explanatory gap between particular causes and effects. His hypothesis, then, is that particular causes and effects are united by nomic relations 'holding between state-of-affair types, between universals' (1997: 227). A second-order law can then 'entail the corresponding universal quantification' (1997: 226), which means, in other words, that laws explain the general causal patterns.

The conclusion to draw is that if one thinks arguments concerning explanatory gaps and general patterns provide good reasons for accepting causal NC laws, it seems that one should accept similar arguments in the case of other kinds of necessitation such as grounding. This suggests the following general account of necessitation:

NC Theory: $x$ 's being F necessitates $x$ 's being $\mathrm{G}$ iff, and because, there is a necessary connection (of some kind) between the universals $F$ and $G$

The inclusion of 'because' signifies the explanatory role that NC laws play. When something that is F necessitates that something is G, this is because of the secondorder necessary connection between universals $\mathrm{F}$ and $\mathrm{G} .{ }^{10}$

${ }^{10}$ To be clear, this is not the same thing as saying that something's being $F$, in conjunction with $N(F, G)$, necessitates that something is G. For example, in the case of laws of nature, it would seem misguided to say that something's being $G$ is jointly causally necessitated by something's being $F$ and $N(F, G)$. It is 
Why, then, have NC theorists not previously attempted to extend their theory in the way suggested? I suspect there are several reasons. For one thing, literature on the contemporary notion of grounding has only been on the scene for just over a decade, and the first NC theorists developed their theories much earlier. But there are two more fundamental reasons: (1) Realists about universals, such as Armstrong, tend to adopt a narrow 'sparse' conception of universals, which seems to rule out the sorts of universals that would be needed to generate NC laws concerning, say, grounding, conceptual necessity, mathematical necessity, and so on. (2) As we have seen, NC laws are traditionally thought to involve necessitation relations that are metaphysically contingent; and since grounding and the other forms of non-causal necessitation are not likely to be metaphysically contingent, it has perhaps been assumed that they are not amenable to NC treatment.

Let us tackle issue (1) first. The 'sparse' conception of universals was popularized by Armstrong (1978) and Lewis (1983) and garnered support for quite some time. The motivation for this conception of properties is that we should avoid positing a universal for every predicate we can possibly think of, or else we are left with a very inflated ontology. Lewis's suggestion (1983) on behalf of the universals theorists is to allow sets of individuals (properties in the 'abundant' sense) to provide the semantic values of all predicates, but to insist that only a select few predicates pick out genuine universals. This general project is well motivated, but the problem is that the definitions of sparseness proposed by Armstrong and Lewis are geared mainly towards the properties of fundamental physics. For Lewis, for example, the fundamental properties are those that 'need nothing bigger than a point at which to be instantiated' (1986b: ix). A similar idea is to be found in the work of Heil, albeit within a metaphysics of modes rather than universals. On Heil's view, the only genuine properties are those of 'simple substances' (2012: 56), and all other properties are merely 'quasi-properties'. However, there is an increasing feeling, especially in the grounding literature, that this sparse conception properties is too sparse. Non-fundamental properties might be derivative but they still 'count ontologically', given that they are not numerically identical with the properties that ground them (Bennett, 2017: 222; see also Schaffer, 2009). Moreover, just because an entity is not itself absolutely fundamental, it can surely still provide perfectly good explanations for other entities that are less fundamental than itself, as we see in the special sciences. Indeed, properties from all levels of science are able to play the roles typically assigned to sparse properties, such as tracking similarities and figuring in scientific laws (Schaffer, 2004). So it seems that non-fundamental entities have important theoretical roles to play. In the case of universals, then, why not allow that some universals are non-fundamental but nonetheless genuine? Indeed, in places even Armstrong seems to appreciate this point. He acknowledges the existence of structural universals like 'being methane' which are composed (in a non-mereological way) by more fundamental universals. Hence, there is arguably a

Footnote 10 continued

arguably a level confusion to think that second-order laws are themselves causes or effects. Rather, the laws are what explain why one thing causally necessitates another. See Bader (2017: 117), who makes a similar point in relation to normative laws. 
tension in Armstrong's sparse conception of universals, as Schaffer notes (2004: 96).

Here is my diagnosis of the problem. Armstrong and Lewis formulated their definitions of sparseness with the idea in mind that we should read off the ontology of universals from the fundamental laws of nature (see in particular Lewis, 2009: 205). This, together with a reductionist presumption in favour of physics, leads to a restricted view of what can count as a genuine universal. If this route is taken, it is hardly surprising that the theory of universals can only accommodate the sorts of laws we find in fundamental science. Other laws concerning grounding necessity, categorial necessity, conceptual necessity, mathematical necessity, etc., will automatically be ruled out. Indeed, because the genuine universals are said to be those that carve out the causal powers, mathematical and concept universals are immediately precluded, because they do not seem to be the sorts of things that have causal power.

In sum, the cards have been stacked against a more wide-ranging $\mathrm{NC}$ theory from the start. But as explained, there is an increasing feeling in recent literature that the Armstrong-Lewis conception of sparse properties is too restrictive (see e.g. Schaffer, 2004; Jubien, 2009; Audi, 2012). If we are willing to relax these restrictions, universals can perform new important work in the area of modality.

Regarding point (2): We said that NC laws are traditionally characterized as being metaphysically contingent, but if there were NC laws concerning, say, grounding necessities and mathematical necessities, it is perhaps doubtful that they would be metaphysically contingent. It is hardly surprising, then, that traditional NC theorists have not extended the view in the way suggested. However, the important point to emphasize, again, is that the metaphysical contingency of NC laws is an optional feature of an NC theory. Armstrong accepts the metaphysical contingency of laws because he ultimately accepts a Humean conception of properties, on which they are loose and separate thin quiddities. On this view, the only difference between universals (of the same adicity) is a bare numerical difference (1997: 168), and the causal powers conferred by properties are not part of their identity. Universals, for Armstrong, are intrinsically non-modal. But for those who lack sympathy for Humean conceptions of properties, there is no good reason why laws cannot be metaphysically necessary. And, indeed, contemporary philosophy has seen significant movement towards anti-Humean theories on which NC laws are metaphysically necessary. These metaphysical necessary connections can be internal or external. Both versions of the NC view have been held in the case of natural law. For example, Fales (1990) holds that laws are external but noncontingent relations between universals, whereas some nomic essentialists (e.g. Swoyer, 1982) and dispositionalists (e.g. Ellis, 2001; Bird, 2007) hold that the necessary connections between universals are internal. We now look in more detail at the different ways in which necessary connections between universals can arise. 


\section{The varieties of $\mathrm{NC}$ laws}

That there are different kinds of necessitation relations is particularly evident in recent grounding literature. Above, we saw how on Dasgupta's version of 'connectivism' (2014) the general modal connections between things are generated by the essences of grounded entities. This view looks rather like a grounding analogue of the dispositional essentialist view of natural laws. On both views, we can say that internal second-order connections are part of the essence of certain type-level entities. Schaffer (2017b), on the other hand, rejects the essentialist conception of laws of metaphysics and proposes instead a 'minimal' primitivist conception. Schaffer does have positive things to say about the grounding laws, including the idea that they have a functional form. However, as we shall see later, Schaffer thinks that laws of metaphysics are not susceptible to any deeper level of analysis and therefore treats them as primitive metaphysical posits. This leaves him with a view about metaphysical laws that is analogous to the Carroll-Maudlin primitivist view of natural laws. In fact, few people have considered an NC account of grounding laws and the laws of metaphysics generally. Bennett (2017: 211) does briefly mention the possibility of a Dretske-Tooley-Armstrong-style account of grounding laws, but it is certainly not a position that Bennett explores or endorses. However, such an approach could bring significant benefits. For example, Dasgupta's essentialist connectivism could be made more perspicuous by being developed in NC terms, and, for reasons given below, the NC theory can even accommodate Schaffer's thought that laws are in some sense primitive.

Regarding Dasgupta's essentialist connectivism about grounding, we have seen already that there are other essentialist theories which posit NC laws. Again, the NC theory does not rule out essentialist accounts of the relevant laws. Dispositionalists like Bird (2007), Ellis (2001) and Mumford (2004) all posit second-order internal necessary connections between universals, and as Barker and Smart explain (2012), these connections must surely play explanatory roles. It is true that dispositionalists sometimes speak as though laws are not entities in their own right. Mumford urges, for example, that an internal connection between universals 'could not count as a metaphysically substantial law of nature' (2006: 464). Here, Mumford is assuming a conception of internal relations on which such relations are no addition of being, or what Armstrong would call an 'ontological free lunch'. That is certainly one way of thinking about internal relations. However, we may distinguish different notions of internal relation. Following terminology introduced by Barker we can draw a distinction between Leibnizian internal relations and Bradlean internal relations. Barker (2009: 247) defines the two notions as follows:

'L-internal: A relation $R$ is internal iff $R$ 's instantiation by relata holds in virtue of monadic features of these relata'

'B-internal: A relation $R$ is internal iff the relata linked by $R$ are, partly or wholly, constituted by their entering into the relation $R$,

Barker urges that if the dispositionalists' second-order connections are constitutive of the essence of universals, as dispositional essentialists generally maintain, then 
they must be Bradlean rather than Leibnizian relations. Such relations constitute the very nature of the relevant universals. But in that case such relations are surely metaphysically substantial, for it is difficult to see how a substantial entity, like a universal, can be constituted by something that is merely an ontological free lunch (see also Tugby, 2016a: Sect. 3.1 and forthcoming 2022: Ch. 3). I agree with Barker on this point. We must be careful not to ignore Barker's Bradlean notion of internality.

Another way for second-order connections not to be ontological free lunches is for them to be external relations of necessitation. On the external view, such connections are not generated merely by the existence of the universals in which they stand. Rather, these relations are in some sense a brute addition. Fales (1990, Ch. 3 and 8) is arguably an example of someone who holds this sort of NC view. Such a view also comes close to the theory that Barker (2013: 611) calls 'brute modalism'.

The point of drawing out these distinctions is that they accommodate different intuitions that people might have about how metaphysically necessary connections arise. I take it to be a virtue of the NC approach that it is flexible about the source of various necessary connections between universals. Importantly, we can accept that different kinds of laws will call for different kinds of relation. For example, if one likes Dasgupta's essentialist connectivism, one can view NC grounding laws as Bradlean internal relations. If, like Schaffer, one dislikes essentialism, then one could view NC grounding laws as necessary external connections or even Leibnizian internal connections. I for one think there are problems for the Bradlean conception of grounding laws. For example, it seems plausible to many people that mental properties are grounded in physical properties, but it seems implausible to think that either physical properties or mental properties are constituted-even partly - by the grounding relations in which they stand. I shall not pursue this issue here, however. The important point for current purposes is that the NC theory is flexible, which means it can accommodate a variety of kinds of necessitation. I suspect, though, that some NC laws will indeed be Bradlean. Earlier I touched upon the view on which concepts are universals: on such a theory, it might well be plausible to think that some concepts are necessarily connected, and if concepts are mutually individuated by their relations to other concepts, as many people maintain, then the relations are likely to be Bradlean.

To round off this section, let us say more about Schaffer's primitivist conception of the laws of metaphysics, which is analogous to the primitivist account of natural laws offered by Carroll (1994) and Maudlin (2007). To be clear, Schaffer does not commit to the primitivist account of natural laws that is held by Carroll and Maudlin. Schaffer notes that one could be a Humean about natural laws, and therefore think such laws are reducible to patterns of behavioural regularity, while also insisting that some metaphysical explanations (concerning grounding, for example) must appeal to irreducible laws of metaphysics (2017b: 316). And such laws, Schaffer argues, are best viewed as primitive, sui generis entities in the same way that Carroll-Maudlin natural laws are. Schaffer is attracted to primitivism about the laws of metaphysics because he thinks that if we try to give a metaphysical analysis of such laws, we will quickly run into trouble. 
Specifically, Schaffer's concern (2017b: 315-16) is that if we try to give a deeper analysis of metaphysical laws in terms of components that are more fundamental (such as universals and the relations between them), we will inevitably need further laws of metaphysics to explain why those components give rise to a law. But then this raises the question of whether this further law can be given a deeper analysis. If it can, then a regress of laws looms. The regress appears to be vicious for the following reason. According to Schaffer, laws are meant to explain their instances in some way, and it is commonly assumed that for an explanation to be satisfactory, it must terminate at some point. ${ }^{11}$ In order to avoid this worry, Schaffer proposes that laws of metaphysics are fundamental sui generis posits. Such laws are not to be analysed further and therefore they provide the explanatory termini that we need. ${ }^{12}$

Schaffer raises an important issue here. Suppose that NC laws are nonfundamental entities that are somehow composed out of (i.e. grounded in) the relevant universals and the necessitation relations in which they stand. What is it that explains this composition? It appears that a higher-order grounding law is needed, but then this inevitably leads to the question of how that higher-order law is grounded in its components.

In order to escape the regress worry without accepting Schaffer's primitivist conception of grounding laws, the NC theorist has two main options. The first is to say that the higher-order grounding law is somehow self-grounding: it explains itself in some sense. Many are sceptical of the idea that facts can explain themselves, but in the case of laws perhaps the idea is not as bizarre as it might seem. Some possible cases of self-subsuming laws are, for example, discussed by Nozick (1981: 119-221). A toy example of such a law is 'every sentence of exactly eight words is true' (1981: 119). There is a lot to be said about this issue, but for the purposes of this paper I tentatively endorse the second option, which involves denying that $\mathrm{NC}$ laws are somehow grounded in ingredients that are more fundamental. If this is right, then the $\mathrm{NC}$ theorists can agree that laws of metaphysics are primitive in some sense. However, the NC theorists can insist that they are not primitive in the sense advocated by Carroll and Maudlin in the case of natural laws, and by Schaffer in the case of metaphysical laws. Unlike those primitivists, the NC theorists will insist that laws have an internal relational structure that we can limn, even though the laws are in some sense prior unities.

The idea here would be that NC laws are ontologically prior to the elements they contain. This kind of ontological priority claim is perfectly coherent. Indeed, Schaffer's own priority monism (2010) has this sort of structure in the case of mereology: wholes are prior to the parts that compose them. Importantly,

\footnotetext{
${ }^{11}$ Schaffer inserts the following caveat: 'Some allow explanations to circle and some allow explanations to never terminate in particular cases, but few would want to say that circular or non-terminating explanatory structures are generally required in all cases, just to avoid fundamental laws of metaphysics' (2017: 316). In what follows, I shall assume that the regress is indeed vicious and examine which NC responses are available. If the regress is not vicious, then of course there is no problem here for the NC theorists in the first place.

${ }^{12}$ Schaffer (2017a, 2017b) applies the worries above to essentialist analyses of the sort given by Dasgupta (2014), but in an email exchange Jonathan Schaffer has confirmed that he thinks the same problem is likely to arise for an Armstrong-style NC theory of metaphysical laws.
} 
Armstrong's metaphysics leads precisely in this direction in the case of laws: the reason for this is that Armstrong's laws are states of affairs-second-order states of affairs, to be precise. States of affairs can be monadic or relational. In the case of NC laws, we have a second-order state of affairs of two or more universals standing in a relation. But on Armstrong's view, states of affairs are primitive unities. For Armstrong, it is states of affairs that are the fundamental ontological units rather than their components. This comes out in various ways, particularly in Armstrong's idea that states of affairs have a non-mereological form of composition and that the components of states of affairs are merely 'vicious abstractions' (see Mumford 2007, Ch. 6 and Tugby, 2016b for discussion). If we take Armstrong's lead on this point, then the NC theory can accommodate the intuition that laws of metaphysics are basic unities.

All this still leaves the question of whether it is the NC or Schaffer-style primitivist account of grounding laws that is the best. I suspect the issue largely comes down to the question of whether one is prepared to accept the metaphysics of universals. Nominalists of various stripes will of course favour the more minimalist view of Schaffer. However, there is an obvious point in favour of the NC view, which is that it provides a more perspicuous account of the nature of laws and their structure. Laws seem to relate different types of entity, and the NC theory takes this structure at face value: laws are relations (of various kinds) between type-level entities. In contrast, primitivists tend to have little to say about what laws, considered as metaphysical entities, are like. Recently, Bhogal (2017) has offered a somewhat different version of primitivism, on which laws are taken to be universal generalizations that are primitively true. I find this account more perspicuous, but since the law-like generalizations are simply primitively true, we are still left in the dark as to why the worldly regularities hold, or rather why the propositions expressing those regularities are true. ${ }^{13}$ The NC theory, in contrast, promises to provide a deeper explanation for worldly regularities, because such regularities are constrained by the relations of necessitation between the relevant universals.

There is, however, one other kind of regress worry that the NC theory of grounding faces. If second-order grounding laws are to explain why certain grounding patterns occur at the first-order level of concrete states of affairs, does this mean that third-order grounding laws are needed to explain why the secondorder laws ground their instances? And are fourth-order laws then needed to explain why third-order laws ground their instances? Notice that this regress differs from the one discussed earlier in connection with Schaffer's work. The Schaffer-style regress concerned further laws which supposedly explain how other laws are composed or constituted. The regress we are considering now, in contrast, concerns further laws that are supposedly needed to explain why other laws ground their instances.

Are these further grounding laws needed? I think the answer is plausibly 'no', in which case this regress problem does not get off the ground. For a start, there are reasons for doubting that the relation between laws and their instances is itself one

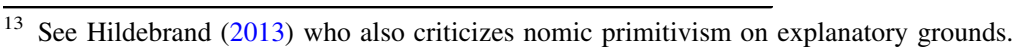


of grounding. One might suspect that it involves a level confusion to say that grounding laws ground grounding, just as it seems confused to say that causal laws cause causation (see footnote 10). Indeed, Schaffer (2017a: 20-21) himself takes this line in relation to grounding principles. But more importantly, it seems that the need for any sort of third-order necessary connection between laws and their instances is obviated by the fact that it is in the nature of laws themselves, qua complex universals, to guarantee their instances. Fortunately, here we can defer on this point to work already carried out by NC theorists. If the laws themselves are complex universals that have various universals as constituents, then the NC theorists should insist that the governing role of the laws is guaranteed from the start. The reason why laws must hold in all cases is simply that they are universals, and universals are identical across their instances. If there is a higher-order universal such that property $F$ necessitates property $G$, then all instances of $F$ must also be $\mathrm{G}$ on pain of metaphysical incoherence (see Armstrong, 1997, Ch. 15.2 for a detailed discussion of this point; see also Tooley, 1987).

\section{Concluding remarks}

Although we have focused mainly on grounding necessitation, I have suggested we might well be able to extend the NC theory in a way that accounts for all different kinds of necessitation. On this view, laws are general connections between entities of many different types. Universals are construed broadly and could potentially include, for example, categorial properties, concepts, and numbers. Although I have not discussed normative necessity in any detail in this paper, I note that Rosen (2017) provides a detailed discussion of the need for normative grounding laws, and we might well think that normative properties could also be given the NC treatment. There is much work to be done on these issues. However, we are at least in a position to articulate our general NC proposal, which recall is as follows:

NC Theory: $x$ 's being F necessitates $x$ 's being $\mathrm{G}$ iff, and because, there is a necessary connection (of some kind) between the universals $F$ and $G$

We have also seen how the necessary connections in question can either be external or internal. The theory is flexible in this respect and could issue different verdicts in different cases of necessitation. In the case of conceptual and mathematical necessities, for instance, one would expect the necessary connections to be internal. For example, in the case of number properties, one would expect the mathematical relationships in which they stand to be necessitated purely by the natures of the properties themselves. For example, given the natures of 8 and 9 , it is necessitated that a group of 9 things is greater than a group of 8 things.

Let us end with a brief speculative thought. If the theory of universals can be extended far enough, perhaps we would have the resources for explaining all kinds of first-order necessity. Earlier we mentioned that Jubien (2009) has a theory of universals on which they stand in internal relations of entailment (see also Tugby forthcoming 2022: Ch. 10, for a detailed discussion of Jubien's framework). 
Importantly, Jubien has a liberal Platonic view of what counts as a property, which includes acceptance of uninstantiated properties. However, although Jubien applies his theory to a variety of modal cases, he never quite provides a general analysis, which has led to criticism (see Turner, 2010; Vetter, 2011). ${ }^{14}$ But perhaps we could utilize the concept of lawhood to at least give an account for all modal truths about first-order, concrete states of affairs. ${ }^{15}$ Note, first, that we could try to analyse such necessities roughly as follows:

NC Account of Necessity: a first-order state of affairs $\psi$ is necessary iff, and because, there is some law that guarantees that $\psi$.

Using the interdefinability of necessity and possibility, we could then analyse firstorder possibility as follows:

NC Account of Possibility: a first-order state of affairs $\psi$ is possible iff, and because, there is no law that guarantees that $\psi$ is not the case.

Notice that this would not be a reductive account, if by 'reductive' we mean that modal concepts are defined in non-modal terms. The right-hand sides of the biconditionals employ the term 'guarantees', which seems to be a modal concept. However, if one thinks the only acceptable analyses of modality are reductive ones, then one is likely to be disappointed. Few theories of modality in the metaphysical literature turn out to be genuinely reductive. ${ }^{16}$ Nonetheless, such theories are illuminating in so far as they try to identify the metaphysical source of modality.

Further work would of course be required to develop this laws-based account of first-order modality and trace out the implications (good or bad) that it has for our modal judgements. I cannot attempt such work here, but I shall briefly note a couple of important issues to be addressed in future work, and finish by comparing the theory with a rival essentialist account of modality.

First, it is not entirely clear whether the laws-based account of first-order modality qualifies as an actualist theory. At first glance, all the metaphysical ingredients of the theory-the universals and the relations between them-appear to be actual existents. And even if there are uninstantiated laws, one could presumably still regard them as actual, Platonic entities. However, some critics of Armstrong's

\footnotetext{
14 Turner (2010) also raises other problems for Jubien's theory of modality which, unfortunately, I do not have the space to discuss here.

15 I hesitate to say that laws could account for all necessary truths. This is because some laws might themselves be necessary and we might be reluctant to posit further laws as a way of explaining such necessity, due to the sorts of regress worries discussed earlier. But importantly, even if some laws of modality are themselves necessary, this does not mean that the necessity must go unexplained. As noted earlier, for example, nomic essentialism is an available option for the NC theorist, on which some laws are necessary due to the essences of the universals they relate.

16 For example, it is arguable that Armstrong's combinatorial theory of modality (1989) does not avoid some form of primitive modality (Thomas 1996). Lewis (1986a, Ch. 3) also criticizes certain forms of modal ersatzism for failing to be genuinely reductive. And the reductive credentials of Lewis's modal realism has itself been questioned (see e.g. Lycan 1988, Shalkowski 1994, and Divers and Melia 2002). More recently, Wang (2013) proposes an openly non-reductive theory of modality based on the notion of primitive incompatibility.
} 
NC theory of natural laws have argued that it does not comply with actualist strictures. Armstrong (1997: 79) once argued against the rival dispositionalist account of natural laws on the basis that unmanifested dispositions have the mysterious characteristic of being essentially directed toward non-actual possibilia, i.e. the possible but non-actual manifestations of those dispositions. In response, Handfield (2005) and Bird (2007, Ch. 5.3.2) have argued that if this argument is successful, then it also creates a serious problem for Armstrong's own theory of laws. This is because the nomic ' $\mathrm{N}$ ' relation essentially has implications that go beyond what is actual. For example, assume that it is a law that N(F,G) and that some object $a$ is not $\mathrm{F}$ but might have been. In this case, it will surely be of the essence of the law to ensure that the following counterfactual holds: if $a$ were F, then it would be G. If counterfactuals like this are what partly constitute the essence of nomic relations, then it is arguable that Armstrong's theory of laws is in the same boat as dispositionalism. As Handfield puts it, ' $\mathrm{N}$ may not be a power or disposition, but it is essentially such as to bring about non-actual states of affairs under nonactual but possible conditions' (2005: 458). If this is right, then one could argue that non-actual possibilia are 'part of the being' of Armstrong's laws (Bird, 2007: 106), in which case such laws would not sit well with a fully actualist metaphysics.

This is clearly an important issue in the current context, since it raises the question of whether the laws-based account of modality can be regarded as an actualist theory. It is surely plausible that all NC laws are 'counterfactual entailing', as Handfield puts it (2005: 457). For example, if it is a law that F-things ground G-things, and some object $a$ is not $\mathrm{F}$ but could have been, it is surely part of the theoretical role of the grounding law to ensure that the non-actual $\mathrm{F} a$ would ground an instance of $G$. If this requires a commitment to non-actual possibilia, then the laws-based account of modality will not be a version of actualism, which some may find disappointing.

There are ways of resisting this anti-actualist argument, however. As Bird notes, an NC theorist could employ a 'type-level' response (2007, Ch. 5.3.3), which involves insisting that laws are not directed towards non-actual possibilia but directed instead towards actual universals, which may or may not be instantiated. On this view, uninstantiated universals are actual surrogates for non-actual possibilia: our account of mere possibilities thus need not invoke non-actual possibilia if uninstantiated universals are in the picture. Elsewhere, I have developed this kind of response (Tugby, 2013) in the context of dispositionalism but it could also be applied to the NC theory, allowing it to comply with actualist strictures. I shall not attempt to settle this debate here. However, an examination of this issue is clearly important, because it will help us to determine what we are buying into by accepting the laws-based approach to first-order modality.

A second important question is thrown up by the issue of de re modality. In contemporary philosophy it is commonly accepted that individuals have mindindependent modal properties, such as the property that Fido has of being necessarily an animal. However, if we are to account for such modal facts in terms of universals, it seems we will have to be prepared to accept universals which can 
only be instantiated once, such as being Fido. ${ }^{17}$ Indeed, Jubien's modal framework allows for these kinds of universals, which he calls 'k-essences' (2009: 90). If we accept such universals, then a laws-based account of supposed de re facts may be available. For example, with the universal being Fido in play, we could posit a necessitation relation holding between the property of being Fido and the property of being an animal (see Jubien, 2009, Ch. 4.6 for further discussion).

What this suggests is that if an NC theory of first-order modality is to be feasible, we shall probably have to posit a wide array of universals and substantially revise our conception of de re modality. I leave these issues for future exploration. But even if a fully general, laws-based analysis of modality fails, I hope to have shown that we could still let laws take care of a wide range of necessitations, namely those in which instantiations of universals necessitate others, or necessarily stand in certain relations to others. For example, if our discussion is along the right lines, then NC laws might explain not only causal necessities but also grounding necessities. And if concepts and numbers are universals, the theory might even extend to more abstract cases of necessary connection.

Finally, I note that the laws-based account might enjoy advantages not had by rival theories of modality. One view about modality that is gaining in popularity is the essentialist theory, according to which (roughly) a proposition $p$ is necessary if and only if there is some object whose essence guarantees that $p$. On this view, all necessary truths can be traced to the essence of something. This theory counts Fine (1994), Oderberg (2007), Lowe (2008) and Hale (2013) among its advocates. However, this approach has recently come under fire from those who fail to see how essences deliver a perspicuous explanation of necessity (see e.g. Romero, 2019; Casullo, 2020; Leech, 2020; Mackie, 2020). There remains an explanatory gap, it is thought. In contrast, it is arguable that the laws-based account fares better in this regard because, as we have seen, laws are tailor-made for plugging various explanatory gaps concerning various forms of necessity. ${ }^{18}$ Moreover, I have tentatively argued that the NC theorists have the resources to overcome what are arguably their most serious challenges, namely the regress objections. Nonetheless, it remains to be seen whether a laws-based account of first-order modality is a strong contender, and I welcome further work on the theory.

Acknowledgements I would like to dedicate this paper to the memory of David Armstrong, with whom I had valuable discussions about universals and laws during doctoral supervision meetings. Thanks are due to Stephen Barker, Giacomo Giannini, Jamie Taylor, and the journal referees, who provided very helpful feedback on various versions of the paper. The paper has also benefitted greatly from various discussions and email exchanges with Stephen Mumford, Jonathan Schaffer, Markus Schrenk, Ben Smart, and Michael Wallner. Finally, many thanks to Ben Young for the excellent proofreading work.

Open Access This article is licensed under a Creative Commons Attribution 4.0 International License, which permits use, sharing, adaptation, distribution and reproduction in any medium or format, as long as you give appropriate credit to the original author(s) and the source, provide a link to the Creative Commons licence, and indicate if changes were made. The images or other third party material in this

\footnotetext{
17 I also acknowledge this point in Tugby forthcoming 2022: Ch. 10, Sect. 7.

18 I am grateful to an anonymous referee for emphasizing this point.
} 
article are included in the article's Creative Commons licence, unless indicated otherwise in a credit line to the material. If material is not included in the article's Creative Commons licence and your intended use is not permitted by statutory regulation or exceeds the permitted use, you will need to obtain permission directly from the copyright holder. To view a copy of this licence, visit http:// creativecommons.org/licenses/by/4.0/.

\section{References}

Armstrong, D. M. (1978). Universals and scientific realism, Volumes I and II. Cambridge University Press.

Armstrong, D. M. (1983). What is a law of nature? Cambridge University Press.

Armstrong, D. M. (1989). A combinatorial theory of possibility. Cambridge University Press.

Armstrong, D. M. (1997). A world of states of affairs. Cambridge University Press.

Armstrong, D. M. (2004). Truth and truthmakers. Cambridge University Press.

Audi, P. (2012). Grounding: Toward a theory of the in-virtue-of relation. Journal of Philosophy, 109, $685-711$.

Bader, R. (2017). The grounding argument against non-reductive moral realism. In R. Shafer-Landau (Ed.), Oxford studies in metaethics 12. Oxford: Oxford University Press.

Barker, S. (2009). Dispositional monism, relational constitution and quiddities. Analysis, 69, 242-250.

Barker, S. (2013). The emperor's new metaphysics of powers. Mind, 122, 605-653.

Barker, S., \& Smart, B. (2012). The ultimate argument against dispositional monist accounts of laws. Analysis, 72, 714-722.

Bennett, K. (2017). Making things up. Oxford University Press.

Bhogal, H. (2017). Minimal anti-Humeanism. Australasian Journal of Philosophy, 95, 447-460.

Bigelow, J., \& Pargetter, R. (1990). Science and necessity. Cambridge University Press.

Bird, A. (2007). Nature's metaphysics: Laws and properties. Oxford University Press.

Bliss, R., \& Trogdon, K. (2014). Metaphysical grounding. Stanford encyclopedia of philosophy. https:// plato.stanford.edu/entries/grounding/.

Carroll, J. (1994). Laws of nature. Cambridge University Press.

Casullo, A. (2020). Essence and explanation. Metaphysics, 2, 88-96.

Coates, A. (2021). Essence and the inference problem. Synthese, 198, 915-931.

Dasgupta, S. (2014). The possibility of physicalism. The Journal of Philosophy, 111, 557-592.

deRosset, L. (2013). Grounding explanations. Philosophers' Imprint 13, 1-26. http://hdl.handle.net/2027/ spo.3521354.0013.007.

Divers, J., \& Melia, J. (2002). The analytic limit of genuine modal realism. Mind, 111, 15-36.

Dretske, F. I. (1977). Laws of nature. Philosophy of Science, 44, 248-268.

Ellis, B. (2001). Scientific essentialism. Cambridge: Cambridge University Press.

Fales, E. (1990). Causation and universals. Routledge.

Fine, K. (1994). Essence and modality. Philosophical Perspectives, 8, 1-16.

Fine, K. (2001). The question of realism. Philosophers' Imprint, 1, 1-30.

Hale, B. (2013). Necessary beings: An essay on ontology, modality, and the relations between them. Oxford: Oxford University Press.

Handfield, T. (2005). Armstrong and the modal inversion of dispositions. The Philosophical Quarterly, $55,452-461$.

Heil, J. (2012). The universe as we find it. Oxford University Press.

Heil, J. (2018). Must there be brute facts? In E. Vintiadis and C. Mekios (Eds.), Brute facts (pp. 19-27). Oxford University Press.

Hildebrand, T. (2013). Can primitive laws explain? Philosophers' Imprint, 13, 1-15. http://hdl.handle.net/ 2027/spo.3521354.0013.015.

Hildebrand, T. (2018). Natural properties, necessary connections, and the problem of induction. Philosophy and Phenomenological Research, 96, 668-689.

Jubien, M. (2009). Possibility. Oxford University Press.

Kment, B. (2014). Modality and explanatory reasoning. Oxford University Press.

Leech, J. (2020). From essence to necessity via identity. Mind, 130, 887-908. 
Leuenberger, S. (2014). Grounding and necessity. Inquiry: An Interdisciplinary Journal of Philosophy, 57, 151-174.

Lewis, D. (1973). Counterfactuals. Blackwell.

Lewis, D. (1983). New work for a theory of universals. Australasian Journal of Philosophy, 61, $277-343$.

Lewis, D. (1986a). On the plurality of worlds. Blackwell.

Lewis, D. (1986b). Philosophical papers (Vol. II). Oxford University Press.

Lewis, D. (2009). Ramseyan humility. In D. Braddon-Mitchell \& R. Nola (Eds.), Conceptual analysis and philosophical naturalism (pp. 203-222). MIT Press.

Lowe, E. J. (1993). Are the natural numbers individuals or sorts? Analysis, 53, 142-146.

Lowe, E. J. (2008). Two notions of being: Entity and essence. Royal Institute of Philosophy Supplement, $62,23-48$.

Lowe, E. J. (2013). Forms of thought: A study in philosophical logic. Cambridge University Press.

Lycan, W. (1988). Review of 'On the plurality of worlds.' Journal of Philosophy, 85, 42-47.

Mackie, P. (2020). Can metaphysical modality be based on essence? In M. Dumitru (Ed.), Metaphysics, meaning, and modality: Themes from Kit Fine (pp. 247-264). Oxford: Oxford University Press.

Maudlin, T. (2007). The metaphysics within physics. Oxford University Press.

Miller, J. (2020). The ontology of words: Realism, nominalism, and eliminativism. Philosophy Compass, $15,1-13$.

Mumford, S. (2004). Laws in nature. Routledge.

Mumford, S. (2006). Looking for laws. Metascience, 15, 462-469.

Mumford, S. (2007). David Armstrong. Stocksfield: Acumen.

Nozick, R. (1981). Philosophical explanations. Harvard University Press.

Oderberg, D. (2007). Real essentialism. Routledge.

Romero, C. (2019). Modality is not explainable by essence. The Philosophical Quarterly, 69, 121-141.

Rosen, G. (2010). Metaphysical dependence: Grounding and reduction. In B. Hale \& A. Hoffman (Eds.), Modality: Metaphysics, logic, and epistemology (pp. 109-136). Oxford University Press.

Rosen, G. (2017). Ground by law. Philosophical Issues, 27, 279-301.

Schaffer, J. (2004). Two conceptions of sparse properties. Pacific Philosophical Quarterly, 85, 92-102.

Schaffer, J. (2009). On what grounds what. In D. Manley, D. J. Chalmers, \& R. Wasserman (Eds.), Metametaphysics: New essays on the foundations of ontology (pp. 347-383). Oxford University Press.

Schaffer, J. (2010). Monism: The priority of the whole. The Philosophical Review, 119, 31-76.

Schaffer, J. (2016a). Grounding in the image of causation. Philosophical Studies, 173, 49-100.

Schaffer, J. (2016). It is the business of laws to govern. Dialectica, 70, 577-588.

Schaffer, J. (2017a). The ground between the gaps. Philosophers' Imprint $17 \mathrm{http}: / /$ hdl.handle.net/2027/ spo.3521354.0017.011

Schaffer, J. (2017b). Laws for metaphysical explanation. Philosophical Issues, 27, 302-321.

Shalkowski, S. (1994). The ontological ground of the alethic modality. The Philosophical Review, 103, $669-688$.

Skiles, A. (2015). Against grounding necessitarianism. Erkenntnis, 80, 717-751.

Strawson, G. (1987). Realism and causation. Philosophical Quarterly, 37, 253-277.

Swoyer, C. (1982). The nature of natural law. Australasian Journal of Philosophy, 60, 203-223.

Thomas, H. G. (1996). Combinatorialism and primitive modality. Philosophical Studies, 83, 231-252.

Tooley, M. (1987). Causation: A realist approach. Clarendon.

Tugby, M. (2013). Platonic dispositionalism. Mind, 122, 451-480.

Tugby, M. (2016a). Universals, laws, and governance. Philosophical Studies, 173, 1147-1163.

Tugby, M. (2016). Mirage realism revisited. In F. F. Calemi (Ed.), Metaphysics and scientific realism: Essays in honour of David Malet Armstrong (pp. 13-30). Berlin: De Gruyter.

Tugby, M. (forthcoming 2022). Putting properties first: A Platonic metaphysics for natural modality. Oxford: Oxford University Press.

Turner, J. (2010). Review of M. Jubien, 'Possibility.' Analysis, 70, 184-186.

Van Fraassen, B. (1989). Laws and symmetry. Clarendon Press.

Vetter, B. (2011). Recent work: Modality without possible worlds. Analysis, 71, 742-754.

Wallner, M. (2018). The ground of ground, essence, and explanation. Synthese https://doi.org/10.1007/ s11229-018-1856-y

Wang, J. (2013). From combinatorialism to primitivism. Australasian Journal of Philosophy, 91, 535-554.

Wilsch, T. (2015). The nomological account of ground. Philosophical Studies, 172, 3293-3312. 
Wilsch, T. (2021). The governance of laws of nature: Guidance and production. Philosophical Studies, $178,909-933$.

Wilson, A. (2018). Metaphysical causation. Nô̂s, 52, 723-751.

Yates, D. (2018). Inverse functionalism and the individuation of powers. Synthese, 195, 4525-4550.

Publisher's Note Springer Nature remains neutral with regard to jurisdictional claims in published maps and institutional affiliations. 